\title{
Mental Health and Academic Performance of Students during Covid-19 in Pakistan
}

\author{
Sakina Shakeel ${ }^{1}$, Sawera Sabir $^{2} \&$ Pervez Anwar ${ }^{3}$ \\ ${ }^{1,2,3}$ Department of Biochemistry and Molecular Biology, University of Gujrat, Sialkot Campus, Pakistan. \\ ${ }^{3}$ Department of Biochemistry and Molecular Biology, University of Sialkot, Sialkot, Pakistan. \\ Email: sakinashakeel39@gmail.com ${ }^{1}$, sabirsawera@gmail.com² \& pervez.anwer@uogsiakot.edu.pk ${ }^{3}$
}

DOI: http://doi.org/10.46382/MJBAS.2020.4403

Copyright: (02020 Sakina Shakeel et al. This is an open access article distributed under the terms of the Creative Commons Attribution License, which permits unrestricted use, distribution, and reproduction in any medium, provided the original author and source are credited.

COVID-19 has largely negative impact on the economy, wellbeing and education of the country. In the same way, Pakistan has been prominently affected by the COVID-19. The purpose of this study was to examine the impact of COVID-19 on the mental health and academic performance of the students. The quantitative research design with the help of online cross sectional survey questionnaire the data from 592 students was collected. The study found that 200 students were suffering from mild anxiety, 140 from moderate anxiety and 72 from severe anxiety. The study further found that COVID has affected most of the students in Pakistan. The lockdown has effected the concentration on education of loads of students. The study showed that the online learning had negative impacts on most of the student's learning.

Keywords: Academic performance, Anxiety, COVID-19, Lockdown, Mental health.

\section{Introduction}

Coronavirus Disease 2019 (COVID-19) was identified during December 2019 as untraceable pneumonia in Wuhan, Hubei Province, China (Zhai \& Du, 2020). Thereafter, the international committee on taxonomy of viruses (ICTV) recognizes that the specialist causing COVID-19 is the new coronavirus, an extremely intense respiratory disease, coronavirus-2 (SARS-CoV-2) (Wathelet et al., 2020). Chen and Yuan, (2020) the coronavirus episode is rapidly spreading not only in China but around the world, the World Health Organization (WHO) announced a pandemic on March 12, 2020. The absolute number of confirmed 71.6 million cases and 1.6 million deaths in 216 countries as of November 2020 in the whole world, out of which 46.8 million patients are recovered (Bolatov et al., 2020; Hasan \& Bao, 2020; Mheidly et al., 2020). A number of legislative measures have been adopted to neutralize the risk of the spread of diseases. These measures include travel restrictions, social distancing, quarantines compulsory for the travelers, banning the public gatherings, the closure of all the educational institutions, self-isolations, closure of the businesses, imposition of the lockdowns, curfews and making people to stay at their homes. The stakeholders in several countries around the world have announced isolation, lockdowns or curfew as a measure to stop the rapid spread of the infectious disease. These measures in general negatively affected the health, education, tourism and several businesses (Aqeel et al., 2020; Bhuiyan et al., 2020; Fawaz \& Samaha, 2020; Mheidly et al., 2020; Saraswathi et al., 2020).

The coronavirus pandemic has affected all levels of schooling. Educational institutions around the world (in 192 countries) either closed by accident or made limited layoffs, affecting about 1.7 billion students worldwide (Singh $\&$ Adhikari, 2020). Numerous colleges around the world have either postponed or stopped physical education in order to limit social life and henceforth reduce the transmission of virus. However, these measures lead to more 
accessible clinical and social consequences for both undergraduate and graduate students. In connection with the suspension of the work of classrooms in many schools and colleges, the transition to online education for students and graduate students is becoming more and more urgent. This type of education provides an additional method of limiting contact between the students themselves or between the teachers and students. However, many students do not have access to online education due to the lack of methods or tools because of the digital divide.

On 26th February, 2020, the first case of COVID-19 was identified in Pakistan. In Pakistan, the main COVID-19 instance was discovered on February 26, 2020 (Dhahri et al., 2020). Circumstances arose quickly, and on March 23, 2020, government imposed complete lockdown in the country in order to successfully contain COVID-19. Then, this complete lockdown was transformed into the smart lockdown by the government on 9th May, 2020. But, all the businesses, public places and educational institutions were kept closed during this time period. The mental health of the students particularly at the university level was highly affected because of the constant spread of COVID-19 infection, the blame games, conspiracy theories, myths, isolation, boredom and frustration and family financial losses. Several reports (Ahmed et al., 2020; Aqeel et al., 2020; Dhahri et al., 2020; Mian \& Chachar, 2020; Noor et al., 2020; Singh \& Adhikari, 2020) were published that highlighted the mental consequences of the epidemic for the entire population, students and health workers. But, there was no study conducted on the impact of COVID-19 on the mental health and academic performance of the students in Pakistan. In this way, this study will be a significant contribution in the empirical evidences.

\section{Methodology}

\subsection{The Study Design and Sample}

This study has adopted the quantitative research design. In this way, the data was collected through online google form, which was shared with the individuals on social media and WhatsApp. Initially, 628 individuals returned completed questionnaire, but 36 questionnaires were excluded because these individuals were not current students. So, 592 individuals were included for the final analysis of the study. The written consent form was also attached with the questionnaire and the respondents were free to participate in the research process.

\subsection{Questionnaire Design}

The survey questionnaire is adopted and it is based on two sections. The first section is based on generalized anxiety scale (GAD-7) (Spitzer et al., 2006), which has 7 items to measure the anxiety of the students. The responses were coded as "not at all (0), several days (1), over half the days (2) and nearly every day (3)". Then the scores were added and then cut-off scores are considered as "mild (5-9), moderate (10-14) and severe ( $\geq 15)$ for anxiety". The second section of the study was adopted from (Mahdy, 2020), which is based on 11 questions to measure the impact of COVID-19 on the academic performance of the respondents.

\subsection{Data Analysis}

After collection of the data through survey, the data was put into SPSS version 22. After that, the descriptive Statistics Analysis is used to analyse the impact of the COVID-19 on the mental health and academic performance of the students in Pakistan. 


\section{Results and Discussion}

\subsection{Demographic Data}

In this study, there were total 592 individuals whose responses were included for the final analysis. There were 216 (36.5\%) male students and 376 (63.5\%) female students. The table 1 and figure 1 show the education level of the students who participated in the study.

Table 1: Educational Level

\begin{tabular}{|c|c|c|c|c|}
\hline \multicolumn{2}{|c|}{} & Frequency & Percent & Cumulative Percent \\
\hline \multirow{4}{*}{ Valid } & Intermediate & 64 & 10.8 & 10.8 \\
\cline { 2 - 5 } & Undergraduate & 388 & 65.5 & 76.4 \\
\cline { 2 - 5 } & Masters & 108 & 18.2 & 94.6 \\
\cline { 2 - 5 } & MS/M.Phil & 24 & 4.1 & 98.6 \\
\cline { 2 - 5 } & PhD & 8 & 1.4 & 100.0 \\
\cline { 2 - 5 } & Total & 592 & 100.0 & \\
\hline
\end{tabular}

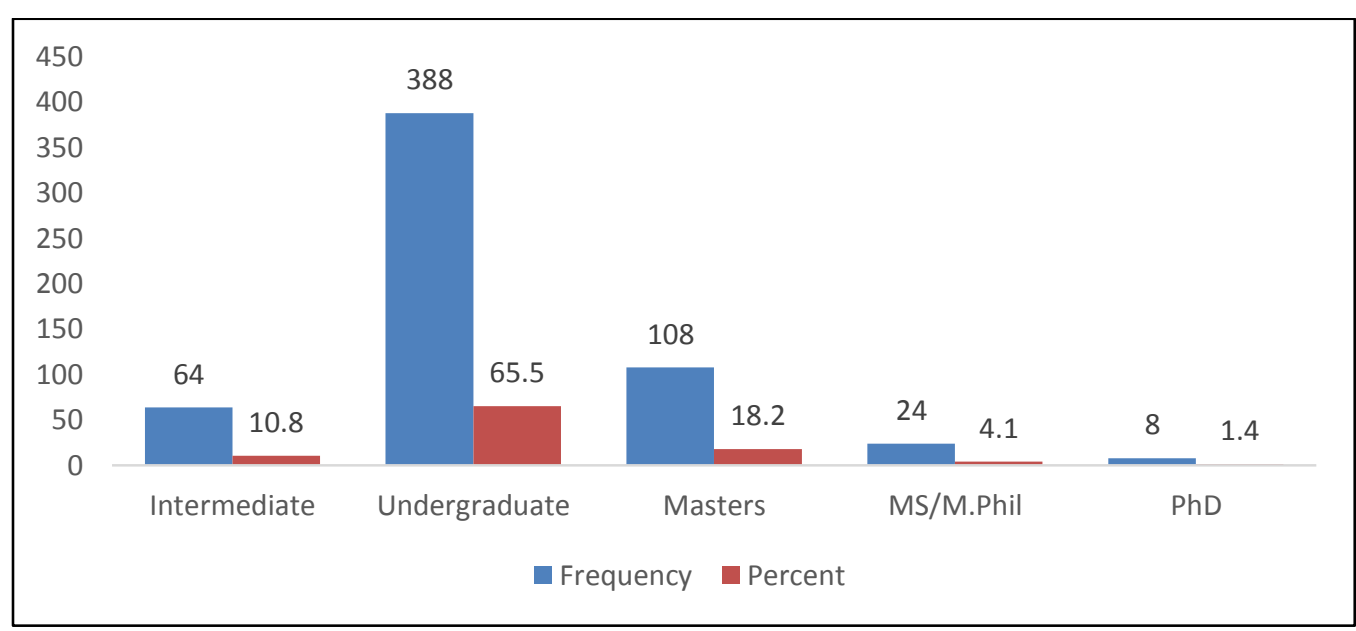

Fig.1. Educational Level

Table 2: Electronic Device Use to Study Online in Lockdown

\begin{tabular}{|c|c|c|c|c|}
\hline \multicolumn{2}{|c|}{} & Frequency & Percent & Cumulative Percent \\
\hline \multirow{4}{*}{ Valid } & Laptop & 244 & 41.2 & 41.2 \\
\cline { 2 - 5 } & PC & 32 & 5.4 & 46.6 \\
\cline { 2 - 5 } & Smart phone & 316 & 53.4 & 100.0 \\
\cline { 2 - 5 } & Total & 592 & 100.0 & \\
\cline { 2 - 5 } & & & & \\
\hline
\end{tabular}




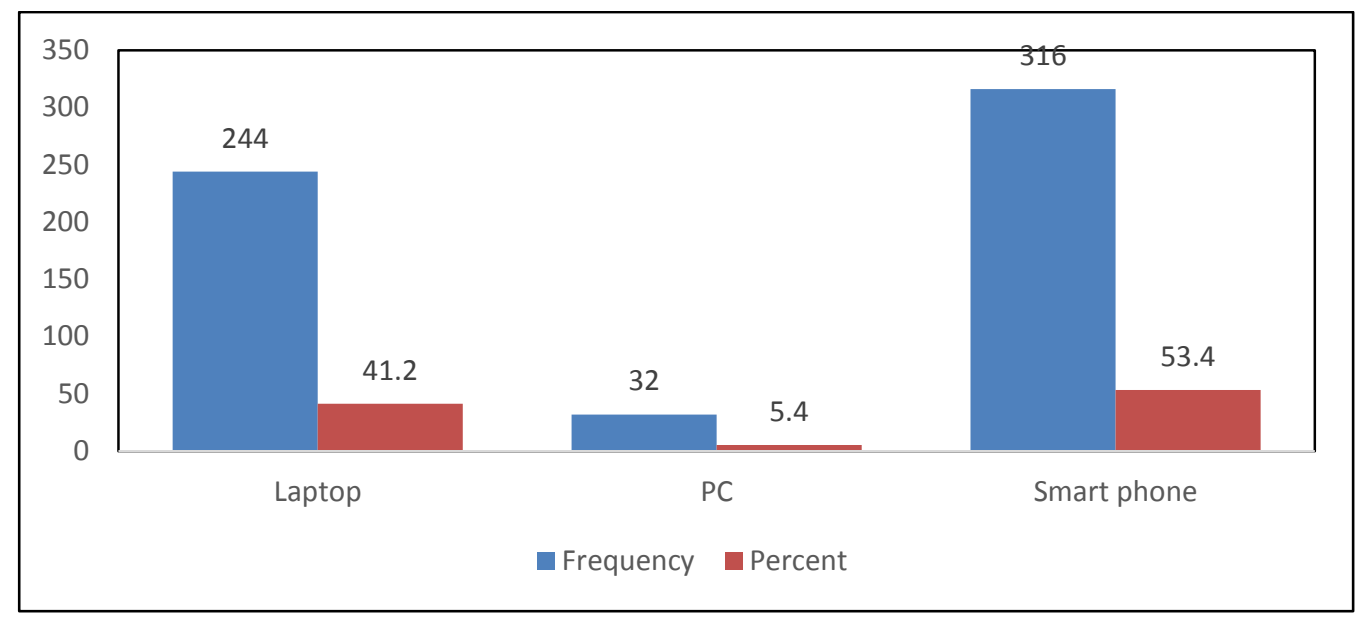

Fig.2. Electronic Device Use to Study Online in Lockdown

There were 64 (10.8\%) students with Intermediate level, 388 (65.5\%) with undergraduate level, 104 (18.2\%) with masters' level, 24 (4.1\%) with MS/M.Phil Level and only 8 (1.4\%) with PhD Level. Table 2 and figure 2 shows the usage of electronic device by the students to study online. The study has found that 244 (41.2\%) use Laptop to

study online, 32 (5.4\%) Use their PCs (Desktops) and 316 (53.4\%) use their smartphones to study online.

According to this data, it is clearly evident that most of the students use their smartphones for their study purpose.

\subsection{Anxiety}

After conducting the demographic analysis, the study analysed the anxiety level among the participants. In this way, the responses of the students were given numeric values and their responses were summarized. After that the scores were calculated to identify the anxiety level. The scores less than 5, were considered as free from anxiety, 5-9 scores were considered to be mild, 10-14 as moderate and equal to or more than 15 were considered as severe. So, the study found that 180 students (76 males, 104 females) did not suffer from anxiety, 200 students (64 males, 136 females) were having mild anxiety, 140 students (60 males, 80 females) were having moderate anxiety and 72 students (16 males, 56 females) were having severe anxiety (table 3 and figure 3 ).

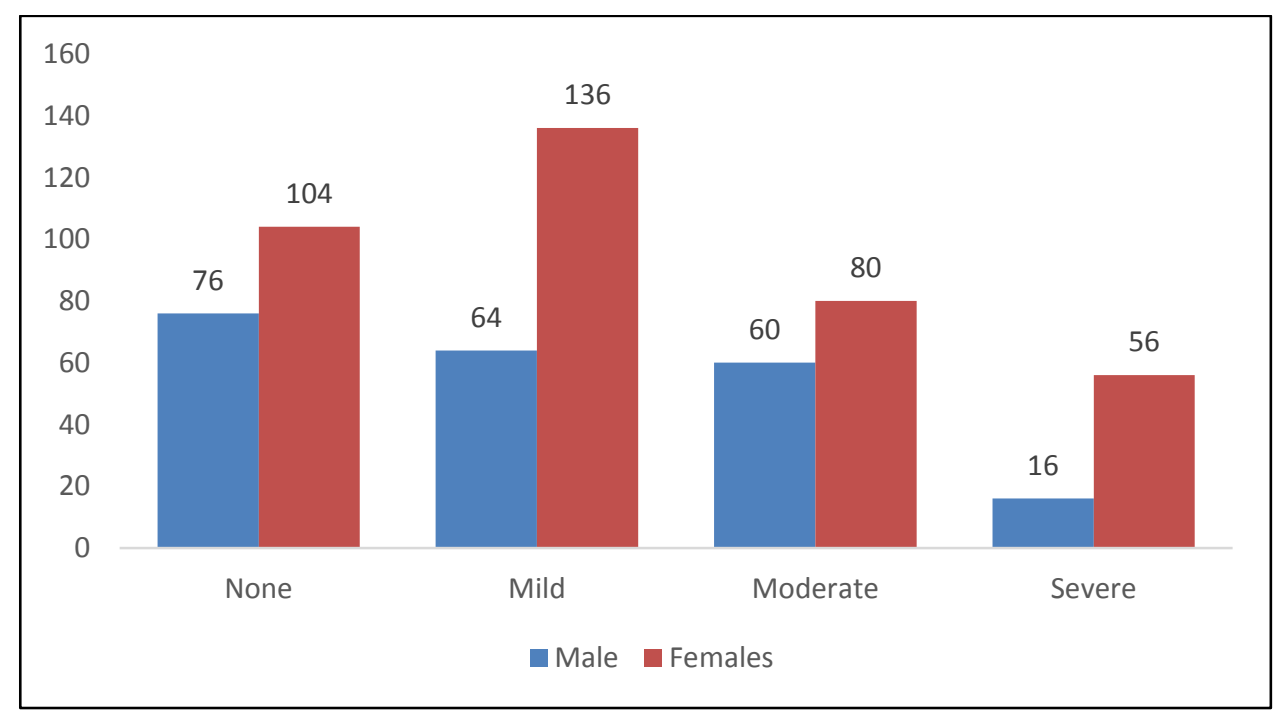

Fig.3. Gender and Total Anxiety 
Table 3: Gender and Total Anxiety

\begin{tabular}{|c|c|c|c|c|c|c|}
\hline \multicolumn{2}{|c|}{} & \multicolumn{4}{|c|}{ Total Anxiety Score } & \multirow{2}{*}{ Total } \\
\cline { 3 - 6 } & None & Mild & Moderate & Severe & \\
\hline \multirow{3}{*}{ Gender } & Male & 76 & 64 & 60 & 16 & 216 \\
\cline { 2 - 6 } & Females & 104 & 136 & 80 & 56 & 376 \\
\hline \multicolumn{2}{|c|}{ Total } & 180 & 200 & 140 & 72 & 592 \\
\hline
\end{tabular}

\subsection{COVID Impact on Academic Performance}

Table 4 and figure 4 show the responses of the students showing how COVID has affected their study. The responses of 32 students ( 34 males, 8 females) showed that it has not affected their study. 40 students (16 males, 24 females) responded that it has slightly affected their study. 132 students (68 males, 64 females) showed that it has moderately affected their study. 100 students ( 24 males, 76 females) expressed that it has considerably affected, 288 students (84 males, 204 females) showed that it has highly affected. The COVID has affected the study of females, it can be because of increasing home chores as they had to stay at home and not allowing other domestic staff at their homes for home chores.

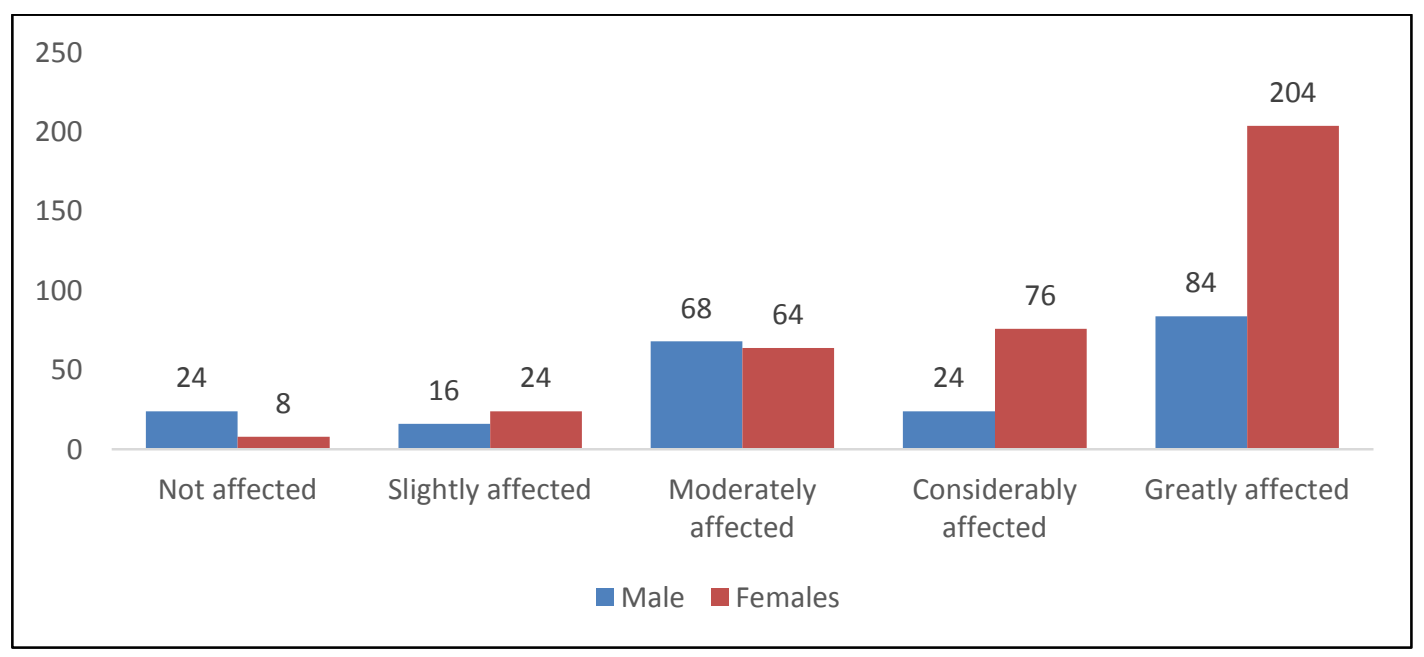

Fig.4. Impact of COVID on Study

Table 4: Impact of COVID on Study

\begin{tabular}{|c|c|c|c|c|c|c|c|}
\hline \multicolumn{2}{|c|}{} & Not affected & $\begin{array}{c}\text { Slightly } \\
\text { affected }\end{array}$ & $\begin{array}{c}\text { Moderately } \\
\text { affected }\end{array}$ & $\begin{array}{c}\text { Considerably } \\
\text { affected }\end{array}$ & $\begin{array}{c}\text { Greatly } \\
\text { affected }\end{array}$ & \\
\hline \multirow{2}{*}{ Gender } & Male & 24 & 16 & 68 & 24 & 84 & 216 \\
\cline { 2 - 8 } & Females & 8 & 24 & 64 & 76 & 204 & 376 \\
\hline \multicolumn{2}{|c|}{ Total } & 32 & 40 & 132 & 100 & 288 & 592 \\
\hline
\end{tabular}


Table 5 and figure 5 show the impact of COVID on Research or project works and the study found that 120 students ( 32 males, 88 females) showed that it has been highly affected, 172 students (72 males, 100 females) showed that it has considerably affected, 156 students ( 76 males, 80 females) responded it has moderately affected, 76 students (20 males, 56 females) showed it has slightly affected and 68 students (16 males, 52 females) showed it has not affected their research or project work. This table shows that higher number of female students is affected by the COVID.

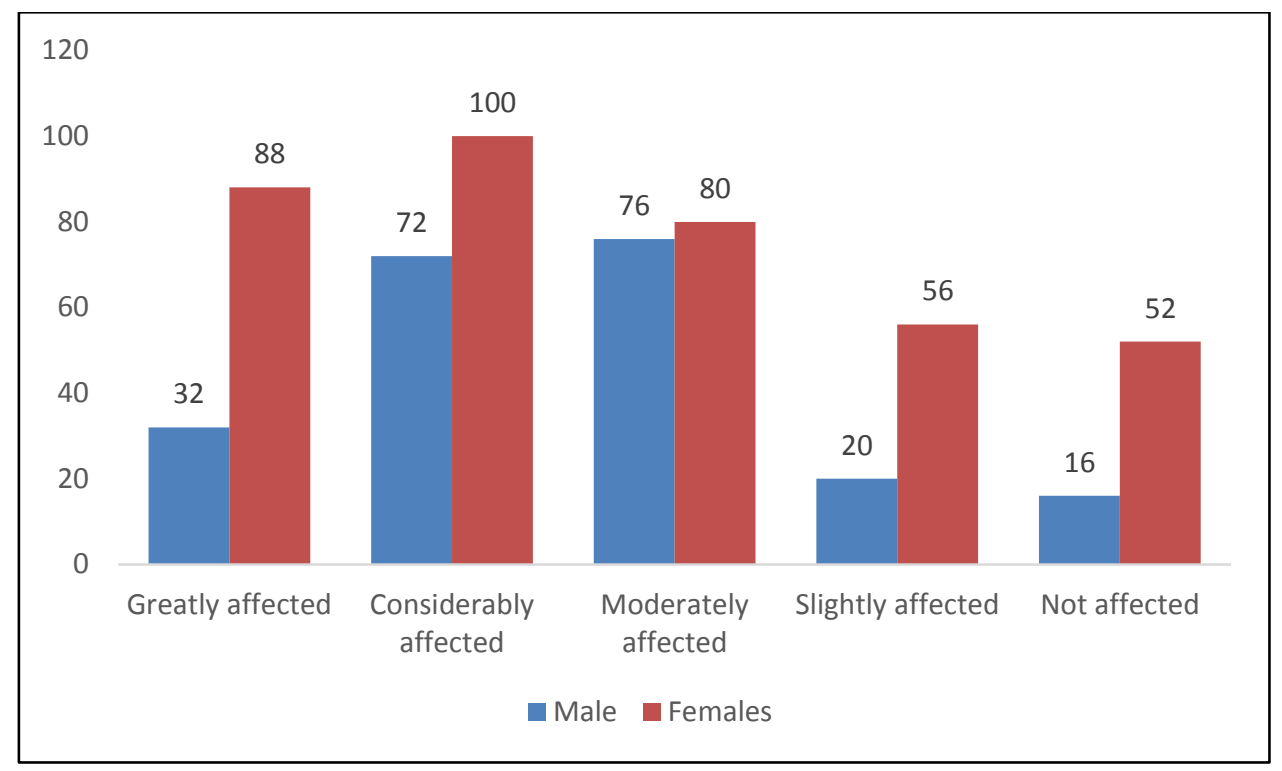

Fig.5. Lockdown Impact on Research/Project Work

Table 5: Lockdown Impact on Research/Project Work

\begin{tabular}{|c|c|c|c|c|c|c|c|}
\hline \multicolumn{2}{|c|}{} & Greatly affected & $\begin{array}{c}\text { Considerably } \\
\text { affected }\end{array}$ & $\begin{array}{c}\text { Moderately } \\
\text { affected }\end{array}$ & $\begin{array}{c}\text { Slightly } \\
\text { affected }\end{array}$ & $\begin{array}{c}\text { Not } \\
\text { affected }\end{array}$ & \\
\hline \multirow{2}{*}{ Gender } & Male & 32 & 72 & 76 & 20 & 16 & 216 \\
\cline { 2 - 8 } & Females & 88 & 100 & 80 & 56 & 52 & 376 \\
\hline \multicolumn{2}{|c|}{ Total } & 120 & 172 & 156 & 76 & 68 & 592 \\
\hline
\end{tabular}

Table 6 and figure 6 show the concentration of the students on their education during lockdown. The study found that 216 students (60 males, 156 females) were highly affected, 136 students (64 males, 72 females) were affected, 104 students (36 males, 68 females) responded that it was moderate, 104 students (52 males, 52 females) responded that it was positively affected and 32 students ( 4 males, 28 females) responded that their concentration was highly increased during lockdown. Table 7 and figure 7 show the responses of the students about the impact of online education on their learning. The higher number of students 248 (60 males, 188 females) responded that online learning has highly affected their learning, 132 students (56 males, 76 females) responded that it has negative impact on their learning, 132 students (56 males, 76 females) responded that it has neutral impact on their 
learning, 48 students ( 28 males, 20 females) responded that it has positive impact and 32 students (16 males, 16 females) responded that it has highly positive impact on their learning process.

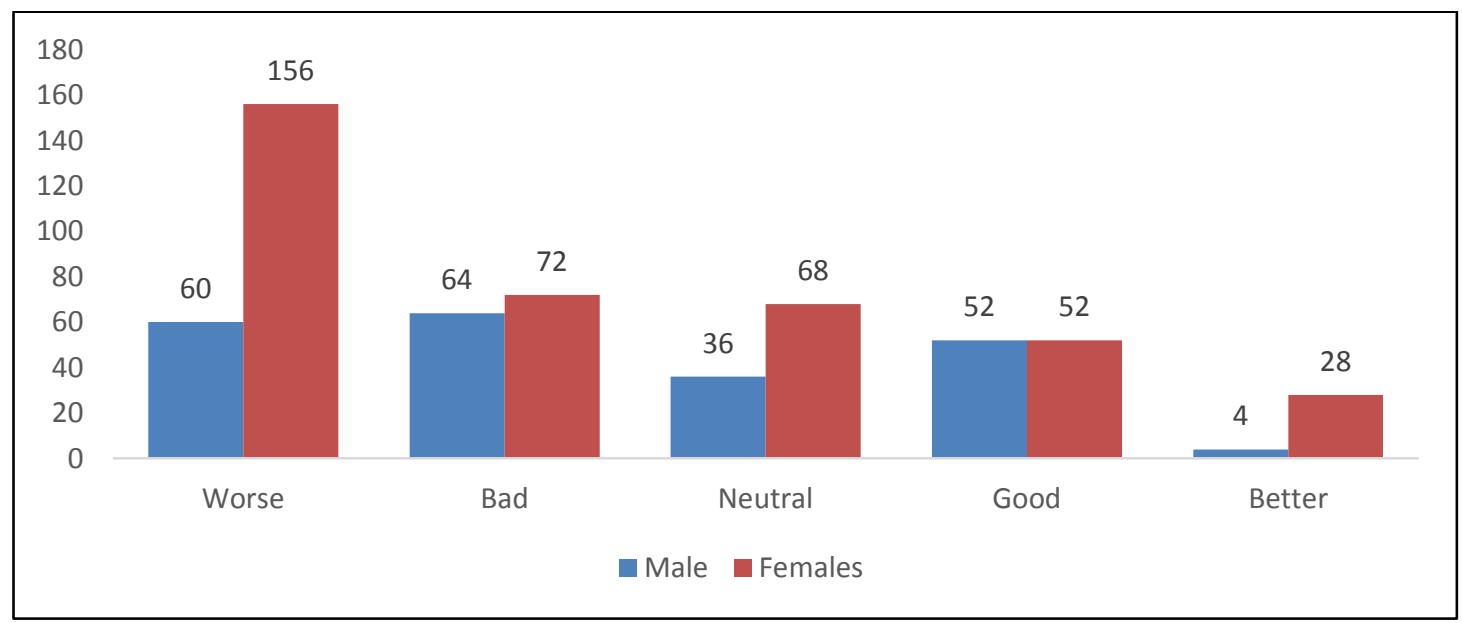

Fig. 6. Concentration on Education during Lockdown

Table 6: Concentration on Education During Lockdown

\begin{tabular}{|c|c|c|c|c|c|c|c|}
\hline \multicolumn{2}{|c|}{} & Worse & Bad & Neutral & Good & Better & \\
\hline \multirow{3}{*}{ Gender } & Male & 60 & 64 & 36 & 52 & 4 & 216 \\
\cline { 2 - 8 } & Females & 156 & 72 & 68 & 52 & 28 & 376 \\
\hline \multicolumn{2}{|c|}{ Total } & 216 & 136 & 104 & 104 & 32 & 592 \\
\hline
\end{tabular}

Table 7: Impact of Online Education on Learning

\begin{tabular}{|l|l|l|l|l|l|l|l|}
\hline \multicolumn{2}{|l}{} & Worse & Bad & Neutral & Good & Better & \\
\hline \multirow{2}{*}{ Gender } & Male & 60 & 56 & 56 & 28 & 16 & 216 \\
\cline { 2 - 8 } & Females & 188 & 76 & 76 & 20 & 16 & 376 \\
\hline Total & 248 & 132 & 132 & 48 & 32 & 592 \\
\hline
\end{tabular}

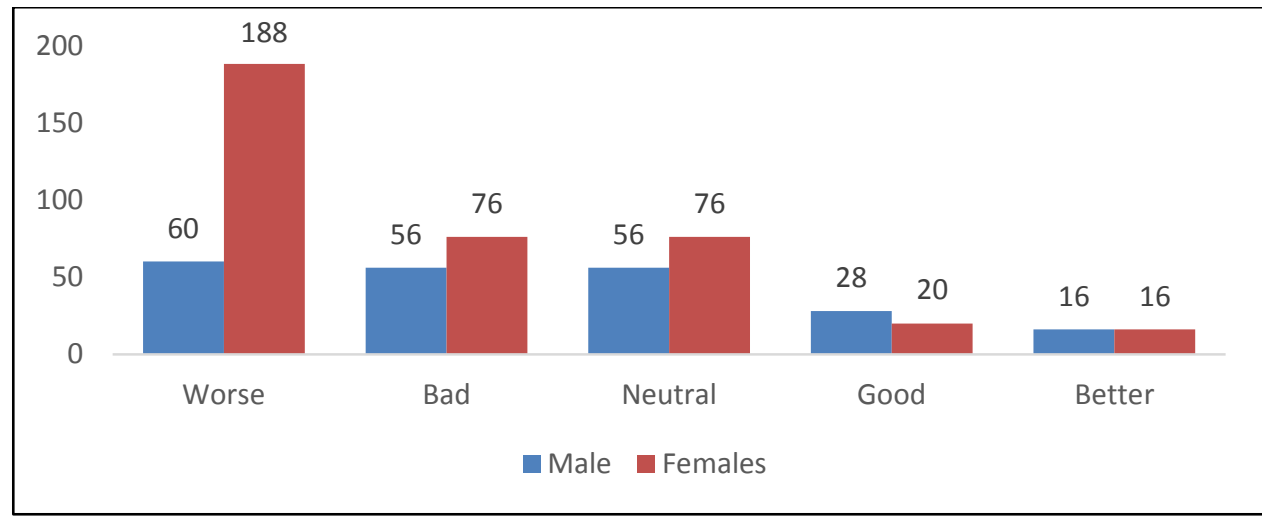

Fig.7. Impact of Online Education on Learning 


\section{Discussion}

This study has found that 69.59 percent of the students are suffering from anxiety (mild, moderate, severe). In the same way, the previous studies (Dhahri et al., 2020; Mahdy, 2020; Mian \& Chachar, 2020; Noor et al., 2020; Saraswathi et al., n.d.; Zhu et al., 2020) have also found the same results that the pandemic has positively significant impacts on the mental wellbeing of the individuals particularly the students. In this way, this is the first study to the best of the researcher's knowledge to be conducted in Pakistan, in which the impact of COVID-19 on the mental wellbeing and academic performance of the students is being assessed. The findings of the study have suggested that online education during this pandemic has highly negative impact on the learning of the students. The reasons can be for the negative impact of online education on learning; technological and digital infrastructure in Pakistan (Aqeel et al., 2020; Bolatov et al., 2020; Swinson, 2006), the low level of technological knowledge among students and teachers (Ahmed et al., 2020; Chen \& Yuan, 2020; Singh \& Adhikari, 2020; Zhai \& Du, 2020). Due to the imposition of lockdown, the research and project work of the students are also highly affected. The concentration on education during this lockdown was also highly affected. Particularly, the female students are highly affected by the lockdown, the reasons can be considered for this as they have to do the home chores, the presence of whole family in the house, may have increased domestic tasks for female students in their houses and they absence of the domestic workers due to the fear of Coronavirus and lockdown.

\section{Conclusion}

COVID-19 has severely affected the human wellbeing at the global level. At the same times, it has also affected the economy and education of the countries. In this way, this is the first study to be conducted in Pakistan that has estimated the impact of COVID-19 on the mental wellbeing and academic performance of the students. The study adopted quantitative research design by implication of online survey through google form. This study has found that 69.59 percent of the students are suffering from anxiety (mild, moderate, severe). In the same way, the previous studies have also found the same results that the pandemic has positively significant impacts on the mental wellbeing of the individuals particularly the students. In this way, this is the first study to the best of the researcher's knowledge to be conducted in Pakistan, in which the impact of COVID-19 on the mental wellbeing and academic performance of the students is being assessed. The findings of the study have suggested that online education during this pandemic has highly negative impact on the learning of the students. Due to the imposition of lockdown, the research and project work of the students are also highly affected. The concentration on education during this lockdown was also highly affected. The findings of the study have also shown that 69.59 percent of the students are suffering from anxiety.

\section{Acknowledgments}

Praise be to Allah Almighty, who provided us the authority, conceptual and physical competences to achieve this research and all admiration for Prophet Hazrat Muhammad (P.B.U.H) for illuminating our faith in Allah. This research is our own struggle and we would like to express our deepest appreciation to those who assisted us in this research especially our supervisor Dr.Pervez Anwar and also one of our professor Dr.Jafar Ali for treasured recommendations to complete this research. 
Mediterranean Journal of Basic and Applied Sciences (MJBAS)

Volume 4, Issue 4, Pages 114-123, October-December 2020

References

[1] Ahmed, M. Z., Ahmed, O., Aibao, Z., Hanbin, S., Siyu, L., \& Ahmad, A. (2020). Epidemic of COVID-19 in China and associated Psychological Problems. Asian Journal of Psychiatry, 51. https://doi.org/10.1016/j.ajp.2020.102092

[2] Aqeel, M., Shuja, K. H., Abbas, J., Rehna, T., \& Ziapour, A. (2020). The Influence of Illness Perception, Anxiety and Depression Disorders on Students Mental Health during COVID-19 Outbreak in Pakistan: A Web-Based Cross-Sectional Survey. https://doi.org/10.21203/rs.3.rs-30128/v1

[3] Bhuiyan, A. K. M. I., Sakib, N., Pakpour, A. H., Griffiths, M. D., \& Mamun, M. A. (2020). COVID-19-Related Suicides in Bangladesh Due to Lockdown and Economic Factors: Case Study Evidence from Media Reports. In International Journal of Mental Health and Addiction. Springer. https://doi.org/10.1007/s11469-020-00307-y

[4] Bolatov, A. K., Seisembekov, T. Z., Askarova, A. Z., Baikanova, R. K., Smailova, D. S., \& Fabbro, E. (2020). Online-Learning due to COVID-19 Improved Mental Health Among Medical Students. Medical Science Educator, 1-10. https://doi.org/10.1007/s40670-020-01165-y

[5] Chen, L., \& Yuan, X. (2020). China's ongoing battle against the coronavirus: Why did the lockdown strategy work well? Socio-Ecological Practice Research, 2(2), 175-180. https://doi.org/10.1007/s42532-020-00048-1

[6] Dhahri, A. A., Arain, S. Y., Memon, A. M., Rao, A., \& Mian, M. A. (2020). "The psychological impact of COVID-19 on medical education of final year students in Pakistan: A cross-sectional study". Annals of Medicine and Surgery, 60, 445-450. https://doi.org/10.1016/j.amsu.2020.11.025

[7] Fawaz, M., \& Samaha, A. (2020). E-learning: Depression, anxiety, and stress symptomatology among Lebanese university students during COVID-19 quarantine. Nursing Forum. https://doi.org/10.1111/nuf.12521

[8] Hasan, N., \& Bao, Y. (2020). Impact of “e-Learning crack-up” perception on psychological distress among college students during COVID-19 pandemic: A mediating role of "fear of academic year loss". Children and Youth Services Review, 118, 105355. https://doi.org/10.1016/j.childyouth.2020.105355

[9] Mahdy, M. A. A. (2020). The Impact of COVID-19 Pandemic on the Academic Performance of Veterinary Medical Students. Frontiers in Veterinary Science, 7, 594261.

[10] Mheidly, N., Fares, M. Y., \& Fares, J. (2020). Coping With Stress and Burnout Associated With Telecommunication and Online Learning. In Frontiers in Public Health (Vol. 8). Frontiers Media S.A. https://doi.org/10.3389/fpubh.2020.574969 
Mediterranean Journal of Basic and Applied Sciences (MJBAS)

Volume 4, Issue 4, Pages 114-123, October-December 2020

[11] Mian, A. I., \& Chachar, A. S. (2020). Debate: COVID-19 and school mental health in Pakistan. In Child and Adolescent Mental Health (Vol. 25, Issue 4, pp. 270-272). Blackwell Publishing Ltd. https://doi.org/10.1111/camh.12431

[12] Noor, S., Ali, M. N., \& Husnine, S. M. (2020). Performance of Online Classes in Lahore, Pakistan During Covid-19. Performance Improvement, 59(9), 33-42. https://doi.org/10.1002/pfi.21938

[13] Saraswathi, I., Saikarthik, J., Senthil Kumar, K., Srinivasan, K. M., Ardhanaari, M., \& Gunapriya, R. (n.d.). Impact of COVID-19 outbreak on the mental health status of undergraduate medical students in a COVID-19 treating medical college: a prospective longitudinal study.

[14] Singh, R., \& Adhikari, R. (2020). Age-structured impact of social distancing on the COVID-19 epidemic in India. In arXiv. arXiv.

[15] Spitzer, R. L., Kroenke, K., Williams, J. B. W., \& Löwe, B. (2006). A brief measure for assessing generalized anxiety disorder: The GAD-7. Archives of Internal Medicine, 166(10), 1092-1097. https://doi.org/10.1001/archinte.166.10.1092

[16] Swinson, R. P. (2006). The GAD-7 scale was accurate for diagnosing generalised anxiety disorder. In Evidence-Based Medicine (Vol. 11, Issue 6, p. 184). https://doi.org/10.1136/ebm.11.6.184

[17] Wathelet, M., Duhem, S., Vaiva, G., Baubet, T., Habran, E., Veerapa, E., Debien, C., Molenda, S., Horn, M., Grandgenèvre, P., Notredame, C. E., \& D’Hondt, F. (2020). Factors Associated With Mental Health Disorders Among University Students in France Confined During the COVID-19 Pandemic. JAMA Network Open, 3(10), e2025591. https://doi.org/10.1001/jamanetworkopen.2020.25591

[18] Zhai, Y., \& Du, X. (2020). Mental health care for international Chinese students affected by the COVID-19 outbreak. In The Lancet Psychiatry (Vol. 7, Issue 4, p. e22). Elsevier Ltd. https://doi.org/10.1016/S2215-0366(20)30089-4

[19] Zhu, N., Zhang, D., Wang, W., Li, X., Yang, B., Song, J., Zhao, X., Huang, B., Shi, W., Lu, R., Niu, P., Zhan, F., Ma, X., Wang, D., Xu, W., Wu, G., Gao, G. F., \& Tan, W. (2020). A Novel Coronavirus from Patients with Pneumonia in China, 2019. New England Journal of Medicine, 382(8), 727-733. https://doi.org/10.1056/nejmoa2001017 